\title{
A Case of Giant Pituitary Adenoma Associated with a Postoperative Mental Disorder That Ultimately Resulted in Bilateral Blindness
}

\author{
Masahiro Tonari $^{\mathrm{a}}$ Yuko Nishikawa ${ }^{\mathrm{a}}$ Junko Matsuo ${ }^{\mathrm{a}}$ Masashi Mimura $^{\mathrm{a}}$ \\ Hidehiro Oku $^{a}$ Jun Sugasawa ${ }^{a}$ Naokado Ikeda ${ }^{b}$ Yoshitaka Kurisu ${ }^{c}$ \\ Tsunehiko Ikeda ${ }^{\mathrm{a}}$ \\ aDepartment of Ophthalmology, Osaka Medical College, Takatsuki-City, Japan; \\ ${ }^{b}$ Department of Neurosurgery, Osaka Medical College, Takatsuki-City, Japan; \\ 'Department of Pathology, Osaka Medical College, Takatsuki-City, Japan
}

\section{Keywords}

Adrenocorticotropic hormone - Pituitary adenoma - Depression - Giant recurrent tumor . Blindness

\begin{abstract}
Purpose: To report the case of a patient with adrenocorticotropic hormone (ACTH)-producing pituitary adenoma who developed a mental disorder after initial surgery that kept him from undergoing scheduled follow-up visits and who ultimately had a giant recurrent tumor that resulted in blindness. Case Report: A 37-year-old male presented with the primary complaint of decreased visual acuity (VA) in both eyes and visual field defects. Visual field examination revealed bitemporal hemianopia. Magnetic resonance imaging (MRI) showed a pituitary tumor of approximately $4 \mathrm{~cm}$ in diameter extending from the intrasellar region to the sphenoid sinus and the suprasellar region. Transnasal transsphenoidal surgery was performed. Immunostaining of tumor tissue collected intraoperatively showed ACTH-positive cells, thus leading to the diagnosis of ACTH-producing pituitary adenoma. Postoperatively, the patient reportedly developed mental disorder that possibly interfered with scheduled appointments or continuous follow-up visits for many years, so we had no postoperative data about the vision/visual filed.
\end{abstract}


Seven years later, he presented with markedly decreased VA (i.e., no light perception) in both eyes. Fundus examination showed bilateral marked optic disc atrophy. MRI showed a larger than 8-cm diameter giant recurrent pituitary adenoma in the suprasellar region, for which craniotomy was performed for partial tumor resection. Preoperatively, his blood cortisol level was low, and the lesion was deemed a nonfunctioning pituitary adenoma. Postoperatively, no significant complications occurred, yet his VA was no light perception OD and light perception OS. Conclusions: Clinicians should be aware that patients with ACTH-producing pituitary adenomas may develop a mental disorder following surgery and possibly be unable to undergo scheduled follow-up, thus illustrating the importance of establishing an adequate patient follow-up system.

\section{Introduction}

Previous studies have reported cases of pituitary adenomas that resulted in bilateral blindness in patients with pituitary apoplexy [1-4], infections [5], surgical stress [6], and complications after radiation therapy $[7,8]$. However, since there have been major advancements in neurosurgery, the occurrence of bilateral blindness due to a recurrent tumor alone is now relatively rare. On the other hand, mental disorders are a known complication associated with ACTH-producing pituitary adenomas [9-12]. Here we report a case of ACTH-producing pituitary adenoma in a patient who was unable to undergo follow-up visits for a long period, possibly due to a mental disorder that reportedly developed after the first surgery. Consequently, he was later found to have a giant recurrent tumor that ultimately resulted in blindness.

\section{Case Report}

A 37-year-old male became aware of decreased visual acuity (VA) in both eyes and visual field defects at around October 2010, and subsequently visited the Department of Ophthalmology, Osaka Medical College, Takatsuki-City, Japan on November 15, 2010 for treatment. At presentation, his best corrected VA was 0.1 in the right eye and 1.0 in the left eye. Light reflex of the left eye was normal; however, slight relative afferent pupillary defect in the right eye was observed. Color fundus examination showed a predominant optic disc atrophy in his right eye (Fig. 1a, b). Goldmann perimetry showed bitemporal hemianopia, and in detail, complete temporal loss and inferonasal defect in the right eye and defects in the temporal half of the left eye (Fig. 1c, d); thus, we suspected the patient to have a pituitary adenoma and subsequently referred him to the Department of Neurosurgery for further examination. Magnetic resonance imaging (MRI) of the sagittal section (Fig. 2a) and the coronal section (Fig. 2b) showed a giant cystic mass of approximately $4 \mathrm{~cm}$ in diameter extending from the intrasellar region to the sphenoid sinus and suprasellar region. The patient was suspected to have the differential diagnosis of either pituitary adenoma or craniopharyngioma, and subsequently underwent transsphenoidal surgery on December 3, 2010. Immunostaining of the patient's tumor tissue, which was collected intraoperatively, showed adrenocorticotropic hormone (ACTH)-positive cells (Fig. 3a, b), thus resulting in a diagnosis of ACTH-producing pituitary adenoma.

The early postoperative course was favorable, yet the patient eventually discontinued presenting for his scheduled follow-up examinations. On November 27, 2017 (i.e., 7 years later), the patient once again presented at our department after being examined by a local physician who suspected that the patient had visual impairment that required a more detailed 


\section{Case Reports in Ophthalmology}

analysis. It should be noted that at that time, he had reportedly developed a mental disorder and subsequently secluded himself in his house. He was diagnosed with depression by a practicing psychiatrist. At presentation, we found that his VA was no light perception in both eyes, and that his pupils were dilated. Moreover, the patient had no reaction to light, and there was no relative afferent papillary defect. In addition, although there were no abnormalities in the anterior eye or the optic media, fundus examination revealed marked optic disc atrophy in both eyes. Thus, we suspected the patient to have optic neuropathy due to recurrent pituitary adenoma, and once again referred him to the Department of Neurosurgery at our hospital. A subsequent MRI examination revealed a giant cystic mass larger than $8 \mathrm{~cm}$ in diameter in the suprasellar region (Fig. 2c, d), and the patient was diagnosed with advanced recurrent pituitary adenoma. On November 30, i.e., 3 days after the initial presentation, an emergent craniotomy was performed for partial resection of the tumor. A preoperative blood test showed that the patient's blood cortisol level was $2.2 \mu \mathrm{g} / \mathrm{mL}$, which is low, as the normal level ranges from 6.24 to $18.0 \mu \mathrm{g} / \mathrm{mL}$, and the lesion at that time was considered to be a nonfunctioning pituitary adenoma. There were no other significant hormonal disorders at the time of re-examination. Moreover, no significant postoperative complications were observed. However, an ophthalmologic examination performed in April 2018 revealed that the patient's VA was no light perception OD and light perception OS.

\section{Discussion and Conclusion}

The primary treatment used for pituitary adenoma is transnasal transsphenoidal surgery, yet the rate of recurrence following surgery is reportedly $6.6 \%$ [13]. The present patient had been diagnosed with ACTH-producing pituitary adenoma based on the histological findings at the time of the first surgery. The recurrence rate of ACTH-producing pituitary adenomas is known to be higher than that of other pituitary adenomas [14]. In general, regular follow-up examination is important for the early detection of recurrence. The follow-up examination includes MRI, blood cortisol measurement, and assessment of systemic symptoms related to other hormonal abnormalities and ophthalmological symptoms such as visual field defects. If possible, complete surgical removal of the tumor during the first surgery is recommended, and patients with residual tumors may undergo drug therapy or radiation therapy [15]. The patient in the present study was unable to visit the hospital for a long time due to a mental disorder that developed after surgery. With no follow-up treatment, the patient developed a giant recurrent tumor larger than $8 \mathrm{~cm}$ in diameter, thus resulting in blindness in both eyes due to significant compression on the visual pathway.

ACTH-producing pituitary adenomas that are characterized by central obesity, typical facial changes, hypertension, etc., are called Cushing's disease [9]. It is known that Cushing's disease is frequently associated with depression [9-12], and that the symptoms of the depression are associated with both elevated and reduced levels of adrenocortical function [16]. Although the present case was not a typical case of Cushing's disease at the time of the initial onset, it is likely that his mental disorder occurred via the same mechanism as that in cases of Cushing's diseases, which ultimately led to social withdrawal. On the other hand, at the time of recurrence, the tumor was gigantic, leading to complete loss of pituitary function and a reduction in cortisol secretion. There is a possibility that the prolongation of the patient's depression was rather associated with an adrenocortical insufficiency. Chronic adrenocortical insufficiency is classified into primary disease due to lesions of the adrenal cortex and secondary disease due to ACTH hyposecretion. Primary chronic adrenal insufficiency is also called 
Addison's disease, and it is known that Addison's disease is also associated with depression $[17,18]$.

At the time of recurrence, the tumor in the present case was a giant nonfunctioning pituitary adenoma, and a nonfunctioning pituitary adenoma is more common in men and often occurs at youth and middle age [19]. Since there are no symptoms due to excessive hormone secretion, patients often have a very large tumor at the time of recurrence [20]. Symptoms include bitemporal hemianopia due to direct compression of the optic chiasm just above the pituitary gland by the tumor. In the present case, the tumor was so large that the compression caused damage to a large region that included the nerve fibers near the optic chiasm, thus leading to severe visual impairment. Usually, patients visit an ophthalmologist before developing a large tumor. This present case was extremely rare, as the patient's concurrent depression prevented him from undergoing regular follow-up visits.

Patients with recurrent pituitary adenomas have been increasingly treated with endoscopic transsphenoidal surgery due to the risk associated with craniotomy; however, the complete resection rate is lower than that in the initial surgery [21,22]. In the present case, we opted to perform a craniotomy because the patient had a very large recurrent tumor. Fortunately, the postoperative course was favorable, and without complications. However, regarding the patient's current visual status, his VA in the left eye is light perception and that in the right eye is no light perception resulting from significant optic disc atrophy after the long-term compression by the tumor.

The findings in this rare case illustrate that clinicians should consider the possibility that patients with pituitary adenomas, especially ACTH-producing pituitary adenomas, may develop a mental disorder at any time during follow-up and subsequently become unable to visit the hospital regularly, thus showing that it is important to establish a system that allows for the adequate follow-up of patients.

\section{Acknowledgement}

The authors wish to thank John Bush for editing the manuscript.

\section{Statement of Ethics}

The protocols of this study were approved by the Ethics Committee of Osaka Medical College, Takatsuki-City, Osaka, Japan.

In accordance with the tenets set forth in the Declaration of Helsinki, prior written informed consent was obtained from the patient.

\section{Disclosure Statement}

There are no conflicts of interest to report for all authors.

\section{Funding Sources}

Not applicable. 


\section{Author Contributions}

M.T., J.S, Y.K. and N.I.: equal contribution of patient management, conception of the paper, data analysis and interpretation manuscript drafting and literature search. Y.N., J.M., M.M. and H.O.: co-writing of the manuscript, literature search. T.I.: design of the paper, co-writing of the manuscript, literature search, manuscript editing and revision as well as final approval. All authors read and approved the final manuscript.

\section{References}

1 Zhu X, Wang Y, Zhao X, Jiang C, Zhang Q, Jiang W, et al. Incidence of pituitary apoplexy and its risk factors in chinese people: A database study of patients with pituitary adenoma. PLoS One. 2015 Sep;10(9):e0139088.

2 Woo HJ, Hwang JH, Hwang SK, Park YM. Clinical outcome of cranial neuropathy in patients with pituitary apoplexy. J Korean Neurosurg Soc. 2010 Sep;48(3):213-8.

3 Sinnadurai M, Cherukuri RK, Moses RG, Nasser E. Delayed pituitary apoplexy in patient with advanced prostate cancer treated with gonadotrophin-releasing hormone agonists. J Clin Neurosci. 2010 Sep;17(9):1201-3.

4 Turgut M, Ozsunar Y, Başak S, Güney E, Kir E, Meteoğlu I. Pituitary apoplexy: an overview of 186 cases published during the last century. Acta Neurochir (Wien). 2010 May;152(5):749-61.

5 Bakker NA, Hoving EW. A rare case of sudden blindness due to a pituitary adenoma coincidentally infected with methicillin-resistant Staphylococcus aureus (MRSA). Acta Neurochir (Wien). 2010 Jun;152(6):1079-80.

6 Couldwell WT, Weiss MH, Rabb C, Liu JK, Apfelbaum RI, Fukushima T. Variations on the standard transsphenoidal approach to the sellar region, with emphasis on the extended approaches and parasellar approaches: surgical experience in 105 cases. Neurosurgery. 2004 Sep;55(3):539-47.

7 Piquemal R, Cottier JP, Arsène S, Lioret E, Rospars C, Herbreteau D, et al. Radiation-induced optic neuropathy 4 years after radiation: report of a case followed up with MRI. Neuroradiology. 1998 Jul;40(7):439-41.

8 Millar JL, Spry NA, Lamb DS, Delahunt J. Blindness in patients after external beam irradiation for pituitary adenomas: two cases occurring after small daily fractional doses. Clin Oncol (R Coll Radiol). 1991 Sep;3(5):291-4.

9 Kelly WF, Kelly MJ, Faragher B. A prospective study of psychiatric and psychological aspects of Cushing's syndrome. Clin Endocrinol (Oxf). 1996 Dec;45(6):715-20.

10 Lambert JK, Goldberg L, Fayngold S, Kostadinov J, Post KD, Geer EB. Predictors of mortality and long-term outcomes in treated Cushing's disease: a study of 346 patients. J Clin Endocrinol Metab. 2013 Mar;98(3):1022-30.

11 Sonino N, Zielezny M, Fava GA, Fallo F, Boscaro M. Risk factors and long-term outcome in pituitarydependent Cushing's disease. J Clin Endocrinol Metab. 1996 Jul;81(7):2647-52.

12 Gold PW, Kling MA, Khan I, Calabrese JR, Kalogeras K, Post RM, et al. Corticotropin releasing hormone: relevance to normal physiology and to the pathophysiology and differential diagnosis of hypercortisolism and adrenal insufficiency. Adv Biochem Psychopharmacol. 1987;43:183-200.

13 Roelfsema F, Biermasz NR, Pereira AM. Clinical factors involved in the recurrence of pituitary adenomas after surgical remission: a structured review and meta-analysis. Pituitary. 2012 Mar;15(1):71-83.

14 Della Casa S, Corsello SM, Satta MA, Rota CA, Putignano P, Vangeli V, et al. Intracranial and spinal dissemination of an ACTH secreting pituitary neoplasia. Case report and review of the literature. Ann Endocrinol (Paris). 1997;58(6):503-9.

15 Mortini P, Barzaghi R, Losa M, Boari N, Giovanelli M. Surgical treatment of giant pituitary adenomas: strategies and results in a series of 95 consecutive patients. Neurosurgery. 2007 Jun;60(6):993-1002.

16 Endo M, Endo J, Notsu K, Note S. Mental status in a patient with isolated ACTH deficiency. Biol Psychiatry. 1983 Mar;18(3):375-83.

17 Fava GA, Sonino N, Morphy MA. Major depression associated with endocrine disease. Psychiatr Dev. 1987;5(4):321-48

18 Musselman DL, Nemeroff CB. Depression and endocrine disorders: focus on the thyroid and adrenal system. Br J Psychiatry Suppl. 1996 Jun;168(30):123-8.

19 Schaller B. Gender-related differences in non-functioning pituitary adenomas. Neuro Endocrinol Lett. 2003 Dec;24(6):425-30.

20 Abouaf L, Vighetto A, Lebas M. Neuro-ophthalmologic exploration in non-functioning pituitary adenoma. Ann Endocrinol (Paris). 2015 Jul;76(3):210-9. 


\section{Case Reports in Ophthalmology}

21 Tajudeen BA, Mundi J, Suh JD, Bergsneider M, Wang MB. Endoscopic endonasal surgery for recurrent pituitary tumors: technical challenges to the surgical approach. J Neurol Surg B Skull Base. 2015 Feb;76(1):50-6.

22 Negm HM, Al-Mahfoudh R, Pai M, Singh H, Cohen S, Dhandapani S, et al. Reoperative endoscopic endonasal surgery for residual or recurrent pituitary adenomas. J Neurosurg. 2017 Aug;127(2):397-408.
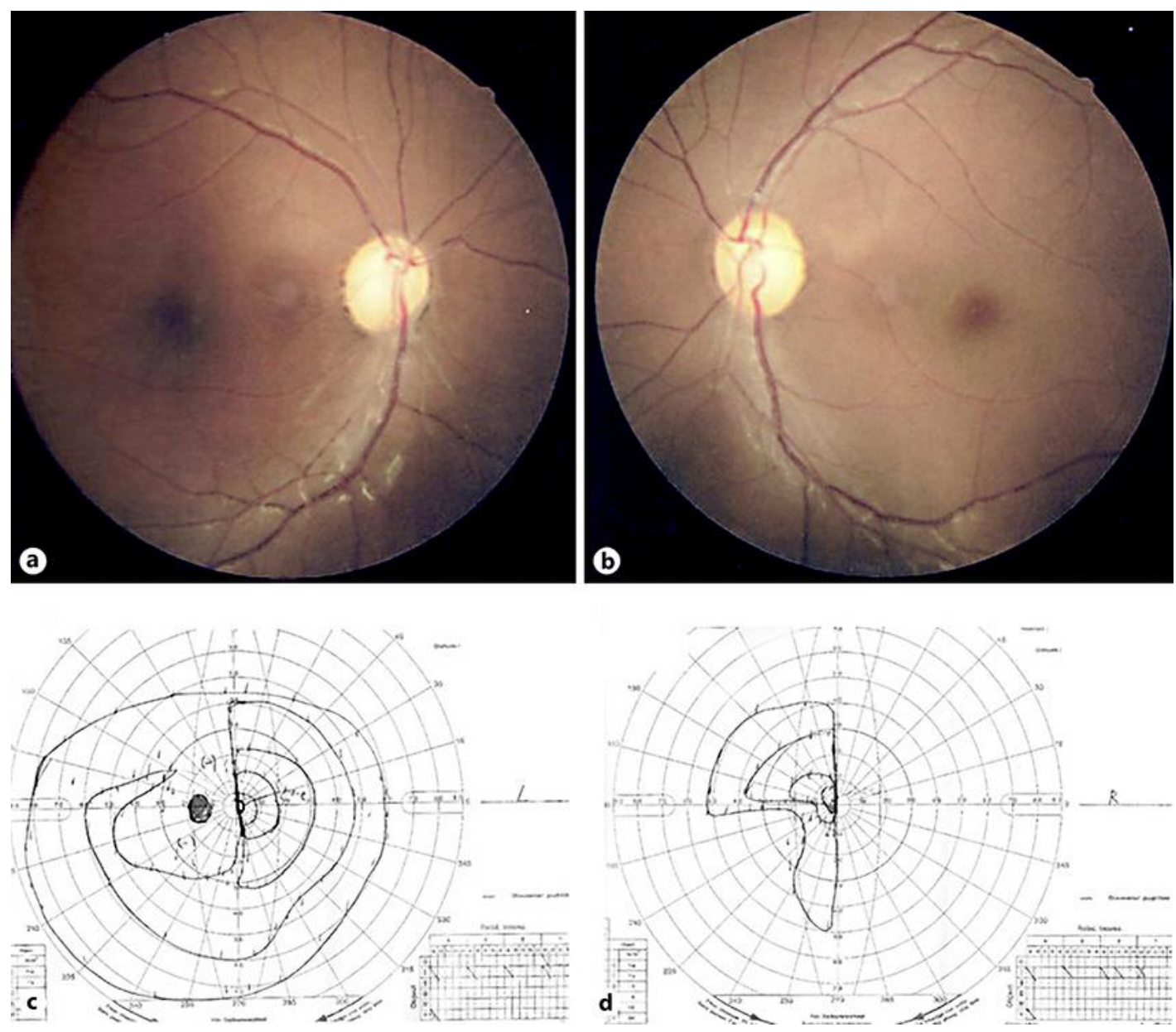

Fig. 1. Fundus photographs (a: right eye, b: left eye) and Goldmann visual field perimetry findings (c: left eye, d: right eye) obtained before the first operation in 2010. Fundus examination showed predominant optic disc atrophy in the right eye. Goldmann perimetry findings showed bitemporal hemianopia, and in detail, complete temporal loss and inferonasal defect in the right eye and defects in the temporal half of the left eye. 


\section{Case Reports in Ophthalmology}
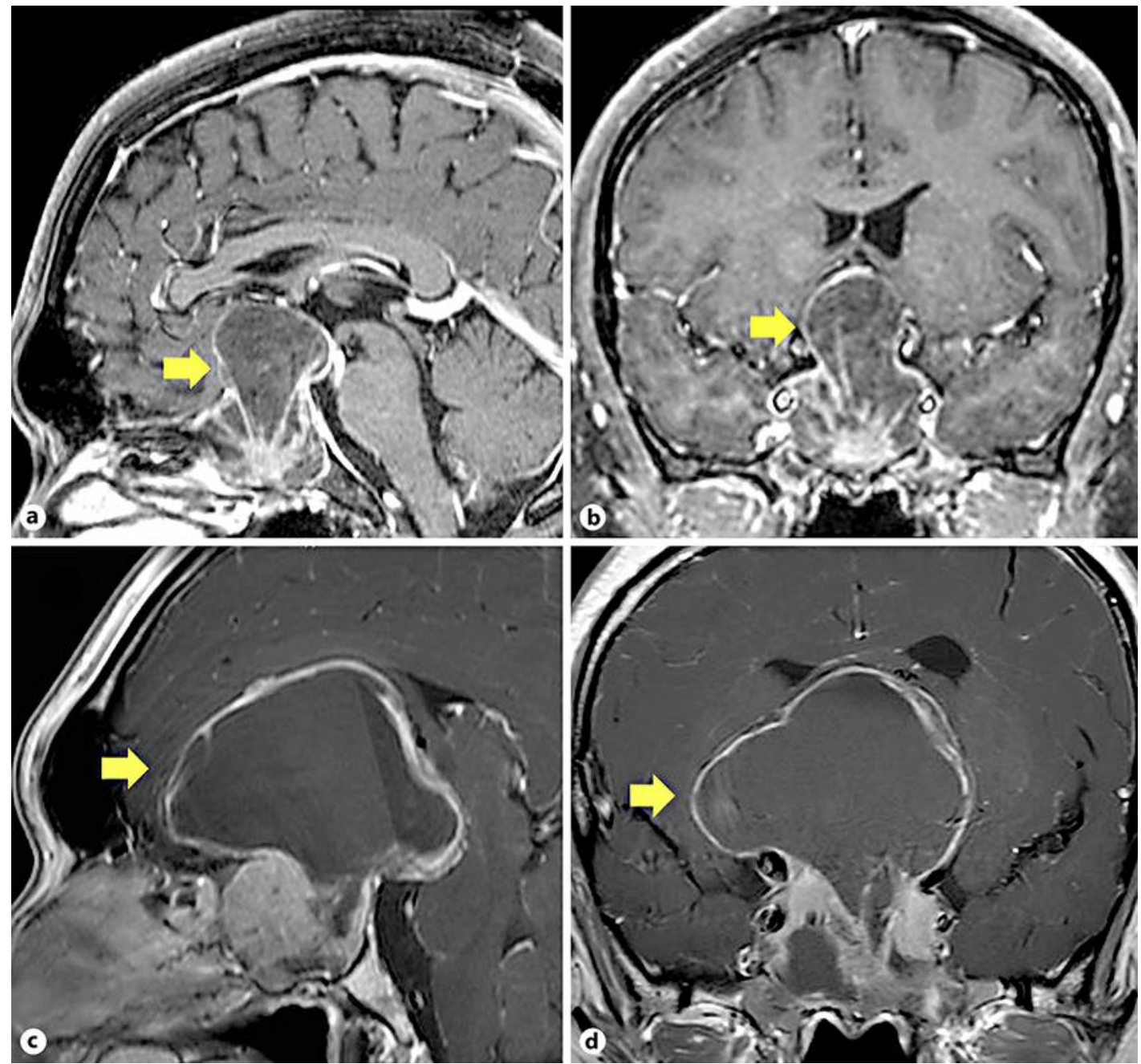

Fig. 2. MRI images of the patient's head obtained before the first operation in 2010 and before the second operation in 2017. Before the first operation in 2010, the MRI sagittal (a) and coronal section (b) showed a giant cystic mass approximately $4 \mathrm{~cm}$ in diameter extending from the intrasellar region to the sphenoid sinus and the suprasellar region. Before the second operation in 2017, the MRI sagittal (c) and coronal section (d) showed a giant cystic mass larger than $8 \mathrm{~cm}$ in diameter in the suprasellar region (T1-weighted image). 


\section{Case Reports in Ophthalmology}
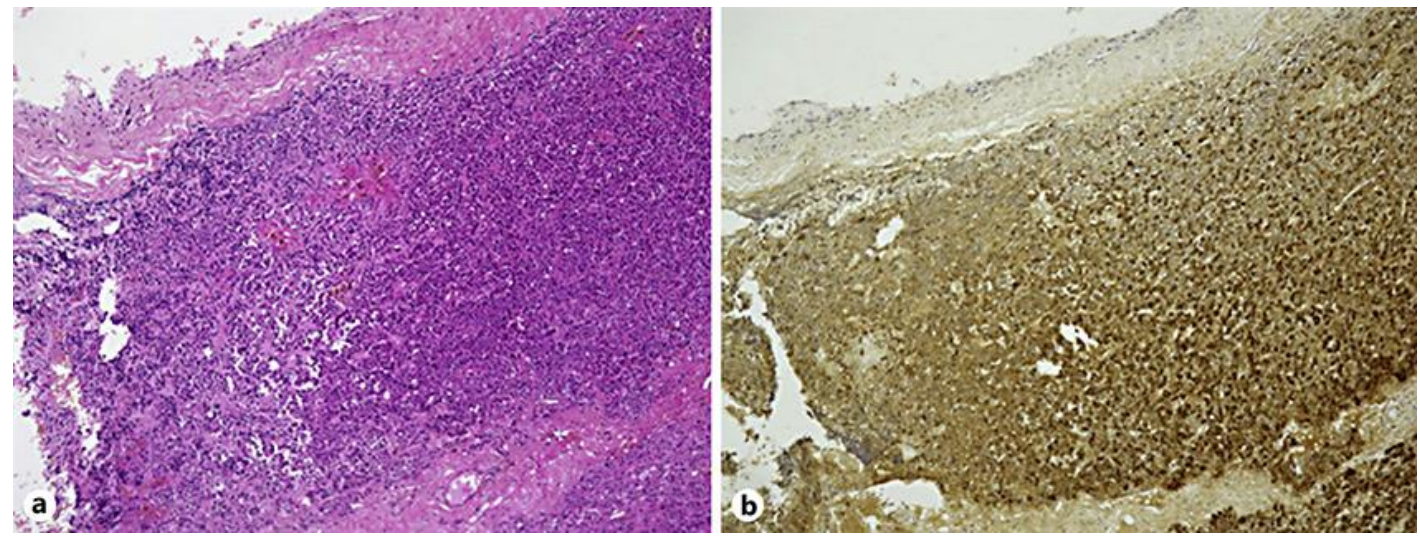

Fig. 3. Histopathological finding of the tumor tissue collected at the first operation (a: hematoxylin and eosin stain, b: immunostaining for ACTH). Immunostaining of the tumor tissue, which was collected intraoperatively, showed adrenocorticotropic hormone (ACTH)-positive cells. 